\title{
CORRECTION
}

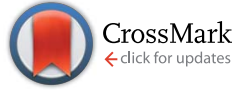

Cite this: J. Mater. Chem. A, 2015, 3, 10610

DOI: 10.1039/c5ta90092a

www.rsc.org/MaterialsA

\section{Correction: Redox-responsive, reversibly fluorescent nanoparticles from sustainable cellulose derivatives}

\author{
Wei Wang, Wei Li and Kai Zhang*
}

Correction for 'Redox-responsive, reversibly fluorescent nanoparticles from sustainable cellulose derivatives' by Wei Wang et al., J. Mater. Chem. A, 2014, 2, 13675-13681.

The author list of the above paper has been corrected to be Wei Wang, Wei Li and Kai Zhang*. Further to this, the acknowledgements section has been revised as shown below.

\section{Acknowledgements}

The authors thank the Hessian excellence initiative LOEWE - research cluster SOFT CONTROL for the financial support. W. L. thanks the China Scholarship Council (CSC) for the financial support. K. Z. thanks Prof. M. Biesalski for the kind support. Mrs S. Starke and Dr J. Appelt (TU Bergakademie Freiberg, Germany) are gratefully acknowledged for the elemental analysis. We thank Dr Yongbiao Yang for Fig. 3 and the helpful discussion.

The Royal Society of Chemistry apologises for these errors and any consequent inconvenience to authors and readers. 